ORIGINAL ARTICLE

\title{
Efficiency of alternative policy options for screening for developmental dysplasia of the hip in the United Kingdom
}

\author{
J Brown, C Dezateux, J Karnon, A Parnaby, R Arthur
}

See end of article for authors' affiliations

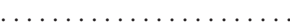

Correspondence to: Dr J Brown, MRC Health Services Research Collaboration, Department of Social Medicine, University of Bristol, Bristol BS8 2PR, UK;

jx.brown@bristol.ac.uk

Accepted

22 January 2003

\begin{abstract}
Aims: To assess, using a decision model, the efficiency of ultrasound based and clinical screening strategies for developmental dysplasia of the hip.

Methods: The additional cost per additional favourable outcome was compared for the following strategies: clinical screening alone using the Ortolani and Barlow tests; addition of static and dynamic ultrasound examination of the hips of all infants (universal ultrasound) or restricted to infants with defined risk factors (selective ultrasound); "no screening" (that is, clinical diagnosis only).

Results: Ultrasound based screening strategies are predicted to be more effective but more costly than clinical screening or no screening. Estimated total costs per 100000 live births are approximately $£ 4$ million for universal ultrasound, $£ 3$ million for selective ultrasound, $£ 1$ million for clinical screening alone, and $£ 0.4$ million for no screening. The relative efficiency of selective ultrasound and clinical screening is poorly differentiated, and depends on how infants are selected for ultrasound as well as the expertise of clinical screening examiners. If training costs less than $£ 20$ per child screened, clinical screening alone would be more efficient than selective ultrasound. Relative to no screening, each of the 16 additional favourable outcomes achieved as a result of selective ultrasound costs approximately $£ 0.2$ million, while each of the five favourable outcomes achieved through universal ultrasound screening, over and above selective ultrasound, costs approximately $£ 0.3$ million.

Conclusions: Policy choice depends on values attached to the different outcomes, willingness to pay to achieve these and total budget.
\end{abstract}

$\mathrm{T}$ he UK national policy to perform a clinical screening examination of the hips on all newborn and very young infants was first introduced in the mid 1960s to identify infants considered at increased risk of subsequent developmental dysplasia of the hip (DDH; formerly referred to as congenital dislocation of the hip). ${ }^{1}$ This policy has never been directly evaluated in a randomised controlled trial and there has been continued controversy and uncertainty about the benefits and harms of screening. The possible iatrogenic effect of avascular of the femoral head is the major disbenefit associated with the overtreatment of those with false positive screening results. ${ }^{2}$ This has culminated in the present interest, both nationally and internationally, in the use of ultrasound in addition to clinical examination. ${ }^{3-5}$ As a consequence, divergent policies now exist, ranging from the universal use of ultrasound in Germany ${ }^{6}$ and Austria, ${ }^{7}$ to the selective use of ultrasound in the USA, ${ }^{8}$ and to clinical screening alone in Canada. ${ }^{9}$ Moreover, in the UK, although current policy recommends clinical screening alone, current practice no longer reflects this policy, with the majority of centres using some form of ultrasound in the assessment process. ${ }^{10}$ In the UK, the National Screening Committee's Child Health Subgroup is therefore reviewing current policy.

Although further research is needed to clarify the benefits and harms of screening and to compare alternative screening strategies, the reality is that policy decisions will be informed by existing information on the relative effectiveness, associated disbenefits, and the costs of alternative strategies. In an accompanying paper, ${ }^{2}$ we have used a decision tree model to compare the clinical effects and performance of clinical screening alone with ultrasound based screening strategies, and with "no screening" in order to inform policy decisions. Our findings suggest that ultrasound screening strategies are more effective, in terms of the number of favourable outcomes without recourse to surgery, than either clinical screening alone or no screening, but clinical screening alone is less clearly differentiated from no screening. We did not consider the efficiency of these strategies, however, which is essential information for decision makers given the ever increasing pressure to fund health care programmes against a background of finite resources.

The aim of this paper is, therefore, to compare alternative ultrasound screening strategies and clinical screening with no screening in terms of their costs and cost effectiveness, using the decision tree model presented in our companion paper. ${ }^{2} \mathrm{~A}$ subsidiary aim is to identify areas where research might help reduce uncertainty relevant to policy decisions.

\section{METHODS}

\section{Characterisation of strategies to be compared}

Strategies to prevent DDH which are applicable to the UK were characterised by considering the variety of policies and practices identified from the literature and a national survey. ${ }^{10}$ These strategies are summarised in detail in the accompanying paper. ${ }^{2}$ Briefly, three screening strategies were identified (see table 1). One is based on clinical screening alone using the Ortolani and Barlow tests to identify infants with hip instability (that is, current policy), while in the other two, ultrasound examination of the hips is added to this clinical screening examination in order to identify abnormalities suggesting hip displacement or instability. In a universal ultrasound strategy, all infants receive an ultrasound examination, while in a selective ultrasound strategy this examination is restricted to infants with a positive Ortolani or Barlow test and/or with recognised risk factors for DDH, including breech presentation at delivery or a positive family history. As the existing policy was introduced without clear evidence of 
Table 1 Definition of screening strategies

\begin{tabular}{|c|c|c|}
\hline Screening strategy & Screening test & Positive test result \\
\hline Clinical screening alone & Ortolani and Barlow tests & Clinically dislocated or subluxatable hip(s) \\
\hline Universal ultrasound & $\begin{array}{l}\text { Ortolani and Barlow tests } \\
\text { AND } \\
\text { Static and dynamic ultrasound imaging }\end{array}$ & $\begin{array}{l}\text { Clinically dislocated or subluxatable hip(s) } \\
\text { OR } \\
\text { Sonographically displaced or unstable hip(s) }\end{array}$ \\
\hline Selective ultrasound & $\begin{array}{l}\text { Ortolani and Barlow tests } \\
\text { AND } \\
\text { Systematic identification of recognised } \\
\text { risk factors for } \mathrm{DDH}^{*}\end{array}$ & $\begin{array}{l}\text { Clinically dislocated or subluxatable hip(s) } \\
\text { OR } \\
\text { Presence of one or more risk factors }\end{array}$ \\
\hline
\end{tabular}

* DDH, developmental dysplasia of the hip. Recognised risk factors include breech (non-cephalic) presentation in third trimester or at delivery, and first degree family history of DDH.

the benefits of screening, we included a no screening strategy, whereby infants are diagnosed following clinical presentation. This reflects the fact that no screening would still incur costs associated with the diagnosis and surgical treatment of infants with DDH. Moreover, the treatment would provide some health benefits. The decision tree depicting the screening and clinical pathways for the alternative strategies is described in the accompanying paper, ${ }^{2}$ where the sources of pathway probabilities are also presented.

\section{Costs}

Table 2 summarises the unit costs, incurred by the health service, associated with the screening and management pathways. All costs were adjusted to 1999/2000 prices, ${ }^{11}$ and considered the costs associated with staff, equipment, overheads, and consumables. Future costs were discounted at a rate of $6 \% .^{12}$ In order to estimate the unit costs we first elaborated how the health service might deliver the screening programme.

\section{Screening costs}

Each screening strategy comprises a clinical examination of the hips (Ortolani and Barlow tests) together with assessment for the presence of risk factors in the newborn, and a further examination at 6 weeks. We assumed that a junior doctor (senior house officer) performed the first test with risk factor assessment on the maternity ward, but that a general practitioner performed the test at 6 weeks. ${ }^{10} \mathrm{~A}$ junior doctor's time was estimated by consultation with clinicians and valued as the wage rate, plus oncosts, uprated by $40 \%$ to take account of overheads. ${ }^{13}$ Published sources of the staff costs associated with the six week examination were uprated by $40 \%$ to take account of overheads. ${ }^{14}$

In addition, under the universal ultrasound screening strategy, the costs associated with screening included the cost of an ultrasound examination on the maternity unit. Staffing levels, time, and equipment associated with the ultrasound examination were modelled on information provided by 58 of the 77 radiologists surveyed who, at the time, were members of the British Society of Paediatric Radiology (BSPR) and were responsible for the ultrasound service in their unit (details available from the authors). Visits were also made to two major centres in the UK operating universal ultrasound screening, supplemented by discussions with other UK centres (see acknowledgements). Staff time was valued as the wage rate derived from published sources, ${ }^{15-18}$ and uprated to take account of oncosts and overheads. The annual equivalent cost of ultrasound equipment was estimated assuming a lifespan of five years and a discount factor of $6 \% .{ }^{19}$

\section{Management costs}

Under the strategy of clinical screening alone, we assumed that a senior doctor would confirm, by repeat clinical examination on the maternity ward, the presumptive positive screening result and refer infants for clinical assessment (that is, without the use of ultrasound) in orthopaedic outpatients prior to a decision to treat or discharge.$^{10}$ The cost of the clinical examination was based on that estimated above for the initial screen, and assuming this was carried out by a specialist registrar. The cost of an initial orthopaedic outpatient consultation was taken from NHS Executive estimates. ${ }^{20}$

\begin{tabular}{|c|c|c|c|c|}
\hline & $\begin{array}{l}\text { No } \\
\text { screening }\end{array}$ & $\begin{array}{l}\text { Clinical } \\
\text { screening alone }\end{array}$ & $\begin{array}{l}\text { Universal } \\
\text { ultrasound }\end{array}$ & $\begin{array}{l}\text { Selective } \\
\text { ultrasound }\end{array}$ \\
\hline \multicolumn{5}{|l|}{ Screen } \\
\hline Clinical examination & - & 1.12 & 1.12 & 1.12 \\
\hline Risk factor assessment & - & 1.12 & 1.12 & 1.12 \\
\hline Examination at 6 weeks & - & 0.78 & 0.78 & 0.78 \\
\hline Ultrasound examination & - & - & 18.63 & - \\
\hline \multicolumn{5}{|l|}{ Management } \\
\hline Repeat clinical examination on maternity ward & - & 1.31 & - & - \\
\hline Initial outpatient visit & - & 90.00 & 121.04 & 121.04 \\
\hline Follow up outpatient visit prior to decision to treat & - & - & 88.04 & 88.04 \\
\hline \multicolumn{5}{|l|}{ Abduction splinting } \\
\hline Pavlik harness & 38.38 & 38.38 & 38.38 & 38.38 \\
\hline $\begin{array}{l}\text { Follow up outpatient visit until treatment } \\
\text { discontinued }\end{array}$ & 75.63 & 75.63 & 75.63 & 75.63 \\
\hline \multicolumn{5}{|l|}{ Surgical treatment } \\
\hline GP visit if symptomatic presentation & 18.00 & 18.00 & 18.00 & 18.00 \\
\hline Open reduction* & 2020.00 & 2020.00 & 2020.00 & 2020.00 \\
\hline Closed reduction* & 1747.48 & 1747.48 & 1747.48 & 1747.48 \\
\hline Follow up to age 16 years* & 1572.00 & 1572.00 & 1572.00 & 1572.00 \\
\hline
\end{tabular}


Table 3 Costs, favourable outcomes*, and incremental cost-effectiveness ratios of the different strategies, ranked by increasing effectiveness (per 100000 live births)

\begin{tabular}{lccccc}
\hline Strategy & $\begin{array}{l}\text { Total costs } \\
(£)\end{array}$ & $\begin{array}{l}\text { Total } \\
\text { favourable } \\
\text { outcomes }\end{array}$ & $\begin{array}{l}\text { Additional } \\
\text { costs (£) } \dagger[A]\end{array}$ & $\begin{array}{l}\text { Additional } \\
\text { favourable } \\
\text { outcomest [B] }\end{array}$ & $\begin{array}{l}\text { Incremental } \\
\text { cost-effectiveness } \\
\text { ratio (£)† [A/B] }\end{array}$ \\
\hline No screening & 380596 & 89.90 & - & - & - \\
Clinical screening alone & 1014537 & 94.05 & 633941 & 4.15 & 152757 \\
Selective ultrasound & 2841295 & 106.15 & 2460699 & 16.25 & 151428 \\
Universal ultrasound & 4394515 & 110.83 & 4013919 & 20.93 & 191778
\end{tabular}

*Favourable outcome refers to radiological appearances at skeletal maturity of Severin grades 1, 2, or 3. †Compared with no screening.

Under the ultrasound based screening strategies, we assumed that infants with a presumptive positive screening result would receive a further clinical examination and an ultrasound assessment as an outpatient, with an average of 1.5 further outpatient assessments (as reported by Marks and colleagues $^{21}$ ) prior to a decision to treat or discharge. The initial and follow up outpatient visits were valued from costs estimated by the NHS Executive. ${ }^{20}$ To this we added the cost of an ultrasound assessment modelled on information obtained from our survey of radiologists and from visits to centres providing universal screening or selective ultrasound examinations in the UK.

\section{Abduction splinting costs}

We assumed that infants with persistent abnormalities following a positive screening result would be treated with abduction splinting using a Pavlik harness ${ }^{1022}$ fitted as an outpatient, and that treatment would be monitored by ultrasound. ${ }^{23}$ An average of 5.5 further outpatient visits for clinical, ultrasound, and radiological assessment prior to discontinuing treatment were based on data collected for the economic evaluation for the UK Hip Trial ${ }^{22}$ (personal communication, Alastair Gray). The Pavlik Harness was costed at manufacturers' prices and the costs of initial and follow up outpatient visits from estimates provided by the NHS executive. $^{20}$ The cost of an ultrasound examination was assumed to be the same as that under the management of infants with presumptive positive screening results.

\section{Surgical treatment costs}

Infants with a presumptive positive screening result but in whom abnormalities are not confirmed at follow up may present clinically at a later stage, when abduction splinting is no longer possible and surgery is required. Similarly, those with a presumptive negative screening result may present later with clinical signs or symptoms. With a policy of no screening we assumed that infants can only present symptomatically and that surgery is the only treatment option.

In the absence of longitudinal data, we based assumptions about the type of surgical treatment given to affected children on expert opinion. Thus we assumed that initially $30 \%$ of infants presenting symptomatically would require an open reduction or osteotomy and $70 \%$ a closed reduction. Of those initially treated with a closed reduction, one fifth would require an open reduction or osteotomy by 3 years of age. ${ }^{24} 25$ We assumed that children in whom initial abduction splinting had been unsuccessful would require closed procedures only. We also assumed that all children presenting symptomatically were referred by their general practitioner for a specialist opinion.

The cost of an open reduction was based on costs provide by the NHS Executive. ${ }^{20}$ The cost of a closed reduction was not readily available and so was based on the percentage difference in cost between a closed and open reduction presented elsewhere. ${ }^{26}$ It was assumed that after surgery, patients would receive, on average, four follow up orthopaedic outpatients visits annually between their first and fifth birthday, and thereafter, annual follow up until the 16th birthday. The cost of the orthopaedic outpatient visits were based on NHS executive estimates and included $x$ ray costs. ${ }^{20}$ For those children presenting symptomatically, the cost of a GP visit was taken from published sources. ${ }^{13}$

\section{Effectiveness}

A favourable outcome was defined as normal hip development assessed by absence of subluxation at skeletal maturity (Severin hip scores of $1-3$ in both hips). ${ }^{27}$ Probabilities of this outcome following abduction splinting or surgery were determined from the literature and used to populate the model in order to estimate the total number of favourable outcomes, per 100000 live births, associated with each screening strategy (details are given in the accompanying paper ${ }^{2}$ ).

\section{Investigating uncertainties in probabilities, outcomes, and costs}

Using extreme but plausible ranges, taken where possible from the literature review, the sensitivity analysis explored the extent to which uncertainties in the costs, screening test performance, service configurations for management, rates of abduction splinting or surgery, and effectiveness of treatment influenced our assessment of the relative efficiency of the strategies.

\section{Modifications to current policy}

As the expertise of the primary screener has been identified as an important factor in the effectiveness of the current policy, ${ }^{48-31}$ we investigated the potential impact of using more experienced examiners by modelling a false negative rate of 0.24 per 1000 live births, equivalent to the average detection rate of $80 \%$ reported from centres using more experienced or specifically trained staff to screen (physiotherapists or orthopaedic specialists). ${ }^{29} 30$ 32-36

The impact of using ultrasound to inform the management of infants with clinical hip instability (positive Ortolani or Barlow tests), as assessed in the UK Hip Trial ${ }^{22}$ was investigated. Costs of ultrasound were added to the follow up costs of those screened positive in the "clinical screening alone" strategy. In addition we assumed that all those with a true positive screening diagnosis were treated initially with abduction splinting - that is, there were no failures of diagnosis among those screening positive. ${ }^{37}$ Finally we investigated a combination of these two modifications to current policy.

\section{RESULTS}

As reported in the accompanying paper, ${ }^{2}$ ultrasound screening strategies are more effective, than either no screening or clinical screening alone, in terms of the number of favourable outcomes achieved, whereas clinical screening alone is less clearly differentiated from no screening. Ultrasound based strategies are, however, more costly (table 3 ).

We assessed the efficiency of each screening strategy relative to no screening by comparing the cost of each 


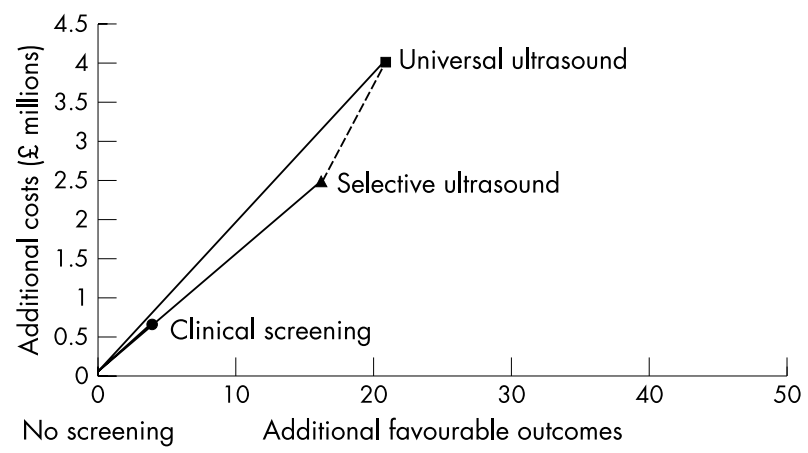

Figure 1 Incremental cost-effectiveness ratios of alternative strategies.

additional favourable outcome as indicated by the incremental cost-effectiveness ratios shown in table 3. These are presented graphically in fig 1 , with each line representing a screening strategy and the slope of the line the incremental costeffectiveness ratio for that strategy relative to no screening. The incremental cost-effectiveness ratios (and therefore the slopes) for selective ultrasound and clinical screening are very similar, suggesting that the efficiency of these strategies is poorly differentiated.

Nonetheless, clinical screening alone is inefficient under the base case assumptions, since it produces fewer favourable outcomes than selective ultrasound and at a higher cost per additional unit of effect. We thus excluded this strategy and estimated the additional costs and additional effects associated with a strategy of universal ultrasound over and above selective ultrasound (table 4). This suggests that, relative to selective ultrasound, a strategy of universal ultrasound would cost about a further $£ 1.5$ million per 100000 live births, or $£ 0.3$ million per additional favourable outcome (table 4 ).* This ratio is depicted in fig $\mathrm{l}$ as the gradient of the dotted line joining the plots for selective ultrasound and universal ultrasound. The key findings of the sensitivity analyses are presented in table 5 (available on the $A D C$ website; www. archdischild.com/supplemental) and are summarised here.

\section{Uncertainties differentiating the policy choice between} selective use of ultrasound and clinical screening alone As well as the obvious effect of increasing the cost of ultrasound, the sensitivity analyses showed two areas of uncertainty, all within the selective ultrasound strategy, which are likely to have a major influence on the relative efficiency of clinical screening alone and selective use of ultrasound. These are: the criteria used to select "high risk" infants for ultrasound and the probability of abduction splinting following a positive screening result.

We investigated uncertainty in the criteria used to select "high risk" infants for ultrasound by varying the percentage of infants with a positive screening result from the base case of $8.1 \%$ to $13 \%$, as reported from some UK centres operating this policy. ${ }^{38}$ Under this assumption, clinical screening alone becomes the efficient option. In contrast, assuming a restricted definition of high risk, such that $4.8 \%{ }^{39}$ are selected for ultrasound, increases the efficiency of selective ultrasound. Thus the efficiency of selective use of ultrasound appears to depend crucially on the way in which "high risk" is defined.

We investigated clinical uncertainty in the indications for splint treatment in a selective ultrasound strategy by varying the probability of abduction splinting following a positive screening result. If we assume a splint rate of 14 per 1000 live

*Current exchange rate: $£ 1 \equiv$ US $\$ 1.5$ or $€ 1.5$ (approx).
Table 4 Costs, favourable outcomes*, and incremental cost-effectiveness ratios of the different screening strategies when compared with the next most effective screening strategyt (per 100000 live births)

\begin{tabular}{|c|c|c|c|}
\hline $\begin{array}{l}\text { Screening } \\
\text { strategy }\end{array}$ & $\begin{array}{l}\text { Additional } \\
\text { costs }(£)[C]\end{array}$ & $\begin{array}{l}\text { Additional } \\
\text { favourable } \\
\text { outcomes [D] }\end{array}$ & $\begin{array}{l}\text { Incremental } \\
\text { cost-effectiveness } \\
\text { ratio }(£)[C / D]\end{array}$ \\
\hline & & & \\
\hline Universal ultrasound $\S$ & & & \\
\hline \multicolumn{4}{|c|}{$\begin{array}{l}\text { *Favourable outcome refers to radiological appearances at skeletal } \\
\text { maturity of Severin grades } 1,2 \text {, or } 3 \text {. } \\
\text { †Recalculated after excluding inefficient screening strategy identified } \\
\text { in table } 3 \text {. } \\
\ddagger \text { Compared with no screening. } \\
\S \text { Ccompared with clinical screening with selective ultrasound. }\end{array}$} \\
\hline
\end{tabular}

births in this strategy (as reported by Rosendahl and colleagues $^{40}$ ), the costs rise, although effectiveness changes very little and clinical screening alone becomes an efficient option. Conversely, a low rate of treatment, 4 per 1000 , modelled from data reported from a specialist UK centre, ${ }^{41}$ makes clinical screening inefficient.

\section{Uncertainties affecting the policy choice of universal ultrasound}

As well as the obvious effect of increasing the cost of ultrasound, the sensitivity analyses showed three areas of uncertainty, two within the selective ultrasound strategy and one within universal ultrasound, which are likely to have a major influence on the relative efficiency of these two strategies. Within the selective ultrasound strategy, these uncertainties are in the criteria used to select "high risk" infants for ultrasound (discussed above), and in the false negative rate for selective ultrasound. If the latter is varied to the higher levels reported from some UK programmes ${ }^{41}(0.73$ per 1000 , equivalent to a detection rate of $48 \%$ ), the effectiveness and, therefore, efficiency of selective ultrasound decreases and selective and universal ultrasound become very similar in terms of efficiency.

In the universal ultrasound strategy, uncertainties in the probability of abduction splinting in universal ultrasound are influential. If we assume the probability of abduction splinting following a positive screening result to be as high as the average reported from European centres operating such a policy (44 per 1000 live births), ${ }^{40} 42$ universal ultrasound becomes very costly and less efficient (total cost: $£ 6$ million per 100000 live births).

Uncertainties affecting the policy choice of no screening The most important factor, identified by the sensitivity analyses, which made any screening strategy less well differentiated from no screening was the probability of an unfavourable outcome following surgical treatment. If the outcome following surgical treatment is better than assumed in the baseline (modelled by halving the probability of an unfavourable outcome after surgery), then all screening strategies become less well differentiated in terms of effectiveness from no screening (fig 2). Under this scenario, clinical diagnosis and management - that is, no screening, produce 105 favourable treatment outcomes compared with 107, 112, and 115 respectively for clinical screening, selective ultrasound, and universal ultrasound, respectively. By contrast, if the outcome following surgery is worse than assumed at baseline (modelled by doubling the probability of an unfavourable outcome), then all screening strategies become well differentiated from no screening. Varying the effectiveness of treatment with abduction splinting does not change the conclusions reached in the baseline analysis (fig 2). 


- Unfavourable treatment outcomes after abduction
splinting doubled
---. Unfavourable treatment outcomes after surgery
halved
--.- Unfavourable treatment outcomes after abduction
splinting halved
$\ldots-\ldots$... Unfavourable treatment outcomes after surgery
doubled
- Base case
- Universal ultrasound
- Selective ultrasound
Clinical screening

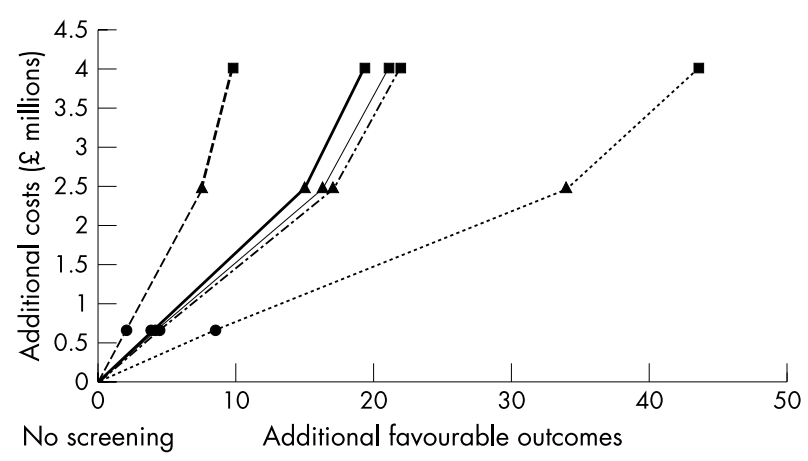

Figure 2 The effect of changing the probability of an unfavourable outcome following treatment.

\section{Modifications to current policy}

Clinical screening alone, when undertaken by more experienced examiners, becomes as effective but more efficient than selective ultrasound. The total annual cost of screening, diagnosis, and management would fall to about $£ 0.8$ million per 100000 live births, reflecting reduced surgical costs. This cost does not include any costs attributable to the extra training required. A threshold analysis showed, however, that up to $£ 20$ per child screened would be available for training before the efficiency of clinical screening and selective ultrasound were similar.

If ultrasound is used to aid the management of infants with clinical hip instability, clinical screening alone becomes an efficient policy and its effectiveness improves, but it remains less effective than the ultrasound strategies.

Finally, we considered both these modifications in combination (excluding the additional training costs). Under this scenario, clinical screening alone becomes the most effective ( 112 favourable outcomes) as well as the least costly screening strategy ( $£ 0.9$ million per 100000 live births). Relative to no screening, each favourable outcome achieved in this scenario costs approximately £0.02 million.

\section{DISCUSSION}

In this paper we distinguished four strategies amenable to policy, in the UK, and used decision analysis to make explicit those factors differentiating the strategies in terms of their effects, costs, and efficiency. ${ }^{44}$ As discussed in our accompanying paper, ${ }^{2}$ the modelling presented here is based, of necessity, largely on observational rather than experimental studies. In particular there has been only limited experimental evaluation of screening or treatment and there are a paucity of studies reporting longer term outcomes. However, our analysis does serve to identify issues that are in need of more rigorous evaluation, and in the interim, provides an accessible framework for decision making by integrating the available data.
Historically the decision to start screening was driven by the perceived delay in diagnosis and poor outcome for children of surgery at that time. Our model predicts that almost three quarters of affected children might expect to have a favourable outcome with no screening - that is, with clinical diagnosis and management alone. However, all affected children will require at least one surgical procedure which is associated with periods of immobility and, as shown in the accompanying paper, ${ }^{2}$ an increased risk of avascular necrosis. The policy choice between screening and no screening is most sensitive to the extent to which surgery achieves favourable outcomes: the more successful surgery, the harder it is to justify screening on the grounds of improved radiological outcome.

The ultrasound based screening strategies appear to be more effective than no screening in that they produce more favourable outcomes for those affected, largely without recourse to surgery. ${ }^{2}$ However, in efficiency terms, policy choices between clinical screening alone and selective use of ultrasound depend crucially on the criteria used to define risk for selective use of ultrasound, the abduction splinting treatment rates in this strategy, as well as the costs of ultrasound. We have highlighted the existing uncertainty in definition of risk. ${ }^{10}$ This uncertainty has implications for important disbenefits, namely those related to avascular necrosis, following treatment of those with false positive diagnoses, ${ }^{2}$ as well as for efficiency. While the findings of the UK Hip Trial ${ }^{22}$ suggest that ultrasound imaging of infants with clinical hip instability allows abduction splinting treatment to be reduced without apparent adverse effects, there is very little similar evidence for infants with risk factors but without clinical hip instability. In the UK there is evidence to suggest clinical equipoise regarding the effectiveness of abduction splinting for infants with risk factors but stable hips. However, the findings of one small randomised trial in this group were inconclusive, ${ }^{45}$ suggesting the need for a larger randomised controlled trial to define treatment benefit in such infants.

A policy of offering ultrasound to all infants appears to be most effective (producing favourable outcome in $92 \%$ of those affected). The risk of avascular necrosis, however, depends crucially on thresholds for treatment with abduction splinting, as shown by sensitivity analyses modelling abduction splinting rates reported from universal ultrasound programmes in other European countries. ${ }^{40} 4243$ Universal ultrasound would also be very resource intensive. Were universal ultrasound screening to be implemented throughout the UK, assuming approximately 700000 births per year, ${ }^{46}$ the total annual cost of screening, diagnosis, and management would be of the order of $£ 31$ million. Indeed it may even be the case that the $£ 20$ million per annum required to implement a policy of selective use of ultrasound throughout the UK is constrained by its budgetary requirements. Clinical screening alone would cost approximately $£ 7$ million and reliance on clinical diagnosis and management without screening for the same population would cost approximately $£ 3$ million. By contrast, universal neonatal screening for hearing loss, which is currently being piloted for implementation, is estimated to cost at least $£ 12$ million per annum (uprated to 1999/2000 prices).$^{47}$

Relative to no screening, the efficiency of clinical screening alone depends critically on the skill of the primary examiner, which in turn reflects the false negative rate. This is consistent with the results of an earlier study by Tredwell. ${ }^{26}$ Modifying the existing policy, by improving the expertise of primary examiners and by using ultrasound examination to image those with clinical hip instability, might be an efficient alternative to abandoning screening. These issues have been discussed in an accompanying paper. ${ }^{2}$ Although there is some evidence from a prospective study ${ }^{48}$ and from a quality improvement initiative ${ }^{49}$ that better training and/or different personnel can reduce the number of children first diagnosed with DDH in late infancy, further research in approaches to 
training would be helpful as there is limited consensus even among experts as to what constitutes an acceptable clinical screening examination. ${ }^{50}$

Although there have been other studies regarding the effectiveness and cost-effectiveness of hip screening, ${ }^{26}{ }^{51-61}$ these have tended to concentrate on estimating the costs of alternative strategies and test performance, for example, in terms of the number of late cases avoided or cases detected by walking age, rather than outcomes at skeletal maturity. Moreover, studies have not been comprehensive in their inclusion of strategies, ${ }^{58} 6061$ while some have evaluated options which are not considered as viable in the UK, such as vibration arthrometry ${ }^{54}$ or pelvic $x$ ray. ${ }^{5253}$ The advantages of the present study include the fact that the effectiveness measure captures the long term outcomes at skeletal maturity and that the alternatives evaluated are those currently relevant to the UK.

As far as possible the unit costs were estimated to reflect the marginal or extra costs of each activity (see table 2) associated with the alternative strategies. Average costs taken from published sources were used, however, for the cost of outpatient visits and surgical treatments. The estimates of surgical costs were nonetheless similar to those reported in the study reported by Clegg and colleagues. ${ }^{61}$ Further comparisons with that study are not possible as it did not report the longer term outcomes. Our model did not consider the costs of treatment beyond skeletal maturity, such as those associated with hip replacement or treatment of avascular necrosis, as reliable information beyond the age of skeletal maturity is not available. We also did not estimate the costs associated with training or quality assurance as UK models are lacking.

The definition of a favourable outcome used in the model to address the relevant efficiency of alternative strategies was based on radiological outcome and is the best objective measure available at present. It may not, however, fully reflect the outcomes most valued by parents. For example, the avoidance of surgery is emphasised by parents groups as being an important concern. The outcome measure also does not combine, at a population level, the value of the benefits of normal hip development and the avoidance of corrective surgery or the avoidance of possible hip replacement in early adult life, with the disbenefits of avascular necrosis which could be captured with utility measures. ${ }^{19}$ Given the time constraint and methodological challenges associated with utility measurement, however, the latter are presented here in a disaggregated form and subject to a value judgement.

The choice between the three screening options and no screening thus depends on the values attached to the different outcomes, how much service providers are willing to pay to achieve these, as well as the total budget available. In the longer term, the model suggests research is needed into measuring the utility values assigned to the screening outcomes, the effectiveness of abduction splinting in children with risk factors but stable hips, and into methods for improving the expertise of examiners responsible for clinical screening.

\section{ACKNOWLEDGEMENTS}

We would like to thank the following for their expert advice and access to data and information that have contributed to this review: Sue Banton, Martin Becker, Mike Benson, Sheila Bird, Patrick Cartlidge, Nick Clarke, John Clegg, David Conlon, Rosemary Dove, Diana Elbourne, Charis Glazener, Alastair Gray, Sara Godward, Marion Hall, Tina Higgins, Edmund Hey, Carol Lefebvre, and members of the British Society of Paediatric Radiology. Much of the work for this paper was conducted while Jackie Brown was a Senior Research Fellow in the Health Economics Research Group at Brunel University.

This work was supported by the Medical Research Council (UK). Work carried out at the Institute of Child Health and GOS NHS Trust benefits from NHS R\&D research funding. The University of Bristol is the lead centre for the MRC Health Services Research Collaboration.

CD is a member of the Child Health Group of the UK National Screening Committee.

\section{Authors' affiliations}

J Brown, MRC Health Services Research Collaboration, Department of Social Medicine, University of Bristol, Bristol BS8 2PR, UK

C Dezateux, Centre for Paediatric Epidemiology and Biostatistics, Institute of Child Health, London WCIN 1EH, UK

J Karnon, A Parnaby, Health Economics Research Group, Brunel University, Uxbridge, Middlesex UB8 3PH, UK

R Arthur, General Infirmary at Leeds, Belmont Grove, Leeds, West Yorkshire LS2 9NS, UK

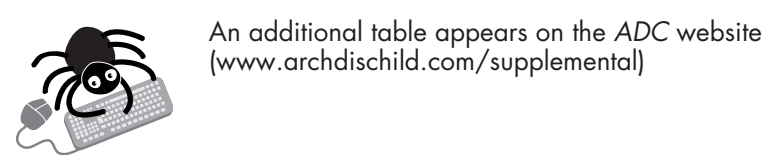

\section{REFERENCES}

1 Standing Medical Advisory Committee. Screening for the detection of congenital dislocation of the hip in infants. London: Department of Health and Social Security, 1966

2 Dezateux C, Brown J, Arthur R, et al. Performance, clinical pathways, and effects of alternative policy options for screening for developmental hip dysplasia in the United Kingdom. Arch Dis Child 2003;88:753-9.

3 Godward S, Dezateux C. Surgery for congenital dislocation of the hip in the UK as a measure of outcome of screening. Lancet 1998;351:1149_ 52

4 Feldman DS. How to avoid missing congenital dislocation of the hip [comment]. Lancet 1999;354:1490-1.

5 Jones D, Dezateux CA, Danielsson LG, et al. At the crossroadsneonatal detection of developmental dysplasia of the hip. J Bone Joint Surg Br 2000;82: 160-4

6 Gunther KP, Stoll S, Schmitz A, et al. [Initial results of the evaluation study of ultrasound hip screening in Germany]. Z Orthop Ihre Grenzgeb 1998:136:508-12.

7 Grill F, Muller D. [Results of hip ultrasonographic screening in Austria] Orthopade 1997;26:25-32.

8 Committee on Quality Improvement SoDDotHAAoP. Clinical practice guideline: early detection of developmental dysplasia of the hip. Pediatrics 2000;105:896-905.

9 Patel H. Preventive health care, 2001 update: screening and management of developmental dysplasia of the hip in newborns. Can Med Assoc J 2001;164:1669-77.

10 Dezateux C, Godward S. A national survey of screening for congenital dislocation of the hip. Arch Dis Child 1996;74:445-8.

11 DoH. Health service cost index. Financial matters. Appendix 1. http://tap.cccta.gov.uk/doh/finman.nsf. Department of Health, 2000 12 HM Treasury. The Green Book: Appraisal and evaluation in central government (Treasury guidance). London: The Stationery Office, 1997.

13 Netten A, Curtis L. Unit costs of health and social care. Canterbury: PSSRU, University of Kent, 2000

14 Sanderson D, Wright D, Acton C, et al. Cost analysis of child health surveillance. Health Technol Assess 2001;5:1-103.

15 NHS Executive. Nurses' and midwives' pay for 1998/89. Advance letter (NM) 1/98, 1998.

16 NHS Executive. Pay and conditions of service of hospital medical and dental staff and doctors in public health medicine and community health service. Advance letter (AC) 1/98, 1998

17 NHS Executive. Administrative and clerical staffs, Whitley council. Advance letter (AC) 1/1998, 1998.

18 NHS Executive. Professions allied to medicine and related grades of staff pay for 1998/99. Advance letter PAM(PTA) 1/98, 1998.

19 Drummond MF, O'Brien B, Stoddart GL, et al. Methods for economic evaluation of health care programmes. Oxford: Oxford Medical Publications, 1998

20 DoH. The New NHS-2000. Reference costs. http://www.doh.gov.uk/ nhsexec/refcosts.htm, Department of Health, 2002

21 Marks DS, Clegg J, Al-Chalabi AN. Routine ultrasound screening for neonatal hip instability. J Bone Joint Surg Br 1994;76-B:534-8.

22 Elbourne D, Dezateux C, Arthur R, et al. Ultrasonography in the diagnosis and management of developmental hip dysplasia (UK Hip Trial): clinical and economic results of a multicentre randomised controlled trial. Lancet 2002;360:2009-17

23 Taylor GR, Clarke NM. Monitoring the treatment of developmental dysplasia of the hip with the Pavlik harness. The role of ultrasound. J Bone Joint Surg Br 1997;79:719-23.

24 Gibson PH, Benson MKD. Congenital dislocation of the hip: review at maturity of 147 hips treated by excision of the limbus and derotation osteotomy. J Bone Joint Surg Br 1982;64-B: 169-75.

25 Sherlock DA, Gibson PH, Benson MK. Congenital subluxation of the hip. A long-term review. J Bone Joint Surg Br 1985;67:390-8.

26 Tredwell SJ. Economic evaluation of neonatal screening for congenital dislocation of the hip. J Pediatr Orthop 1990;10:327-30.

27 Severin E. Congenital dislocation of the hip joint. Late results of closed reduction and arthrographic studies of recent cases. Acta Chir Scand $1941 ;$ LXXIV(suppl 63):7-142. 
28 Macnicol MF. Results of a 25-year screening programme for neonatal hip instability. J Bone Joint Surg Br 1990;72-B: 1057-60.

29 Krikler SJ, Dwyer NSP. Comparison of results of two approaches to hip screening in infants. J Bone Joint Surg Br 1992;74-B:701-3.

30 Fiddian NJ, Gardiner JC. Screening for congenital dislocation of the hip by physiotherapists. Results of a ten year study. J Bone Joint Surg $\mathrm{Br}$ 1994;76-B:458-9.

31 Chan A, Cundy PJ, Foster BK, et al. Late diagnosis of congenital dislocation of the hip and presence of a screening programme: South Australian population-based study. Lancet 1999;354:1514-17.

32 Bernard AA, O'Hara JN, Bazin S, et al. An improved screening system for the early detection of congenital dislocation of the hip. J Pediatr Orthop 1987;7:277-82.

33 Hadlow V. Neonatal screening for congenital dislocation of the hip. J Bone Joint Surg Br 1988;70-B:740-3

34 Poul J, Bajerova J, Sommernitz $M$, et al. Early diagnosis of congenital dislocation of the hip. J Bone Joint Surg Br 1992;74-B:695-700.

35 Lehmann ECH, Street DG. Neonatal screening in Vancouver for congenital dislocation of the hip. Can Med Assoc J 1981;124:1003-8.

36 Barlow TG. Early diagnosis and treatment of congenital dislocation of the hip. J Bone Joint Surg Br 1962;44-B:292-301.

37 Lennox IAC, McLauchlan J, Murali R. Failures of screening and management of congenital dislocation of the hip. J Bone Joint Surg $B$ 1993; 75-B:72-5.

38 Lewis K, Jones DA, Powell N. Ultrasound and neonatal hip screening: the five-year results of a prospective study in high-risk babies. J Pediatr Orthop 1999;19:760-2.

39 Teanby DN, Paton RW. Ultrasound screening for congenital dislocation of the hip: a limited targeted programme. J Pediatr Orthop 1997; 17:202-4

40 Rosendahl K, Markestad T, Lie RT. Ultrasound screening for developmental dysplasia of the hip in the neonate: the effect on treatment rate and prevalence of late cases. Pediatrics 1994;94:47-52.

41 Clarke NMP, Clegg J, Al-Chalabi AN. Ultrasound screening of hips at high risk for $\mathrm{CDH}$ : failure to reduce the incidence of late cases. J Bone Joint Surg Br 1989;71-B:9-12.

42 Rosendahl K, Markestad T, Lie RT. Congenital dislocation of the hip: a prospective study comparing ultrasound and clinical examination. Acta Paediatr 1992;81:177-81.

43 Altenhofen L, Allhoff PG, Niethard FU. [Hip ultrasound screening within the scope of U3-initial experiences]. Z Orthop Ihre Grenzgeb 1998;136:501-7.

44 Royston G. Commentary: trials versus models in appraising screening programmes [comment]. BM 1999;318:360-1.
45 Wood MK, Conboy V, Benson MK. Does early treatment by abduction splintage improve the development of dysplastic but stable neonatal hips? $J$ Pediatr Orthop 2000;20:302-5.

46 Platt MJ. Child health statistics review, 1998. Arch Dis Child 1998;79:523-7.

47 Davis A Bamford J, Wilson I, et al. A critical review of the role of neonatal hearing screening in the detection of congenital hearing impairment. Health Technol Assess 1997:1:i-176.

48 Lee TW, Skelton RE, Skene C. Routine neonatal examination: effectiveness of trainee paediatrician compared with advanced neonatal nurse practitioner. Arch Dis Child Fetal Neonatal Ed 2001;85:F100-4.

49 Maxwell SL, Ruiz AL, Lappin KJ, et al. Clinical screening for developmental dysplasia of the hip in Northern Ireland. BM 2002:324:1031-3.

50 El-Shazly M Trainor B, Kernohan WG et al. Reliability of the Barlow and Ortolani tests for neonatal hip instability. J Med Scr 1994;1:165-8.

51 Fulton MJ, Barer ML. Screening for congenital dislocation of the hip:an economic appraisal. Can Med Assoc J 1984;130:1 149-56.

52 Faure C, Schmit $P$, Salvat D. Cost-benefit evaluation of systematic radiological diagnosis of congenital dislocated hip. Pediatr Radio 1984; 14:407-12

53 Lefaure C, Maccia C, Corlobe F. Cost-effectiveness and risk associated with infants' hip dysplasia screening in France. Ann Radiol Paris 1986;29:393-9

54 Kernohan WG, Trainor BP, Mollan RAB, et al. Cost-benefit appraisal of screening for congenital dislocation of the hip. Journal of Management in Medicine 1989:4:230-5.

55 Marzouk MS. Screening for congenital dislocation of the hip: an economic appraisal [letter]. Can Med Assoc J 1990;143:711.

56 Kernohan WG, Trainor BP, Mollan RAB, et al. Cost of treatment of congenital dislocation of the hip. Int J Health Plann Manage 1991;6:229-33

57 Scottish Needs Assessment Programme. Congenital dislocation of the hip. Scottish Forum for Public Health Medicine, 69 Oakfield Ave, Glasgow G12 8QQ, 1993.

58 Rosendahl K, Markestad T, Lie RT, et al. Cost-effectiveness of alternative screening strategies of developmental dysplasia of the hip. Arch Pediatr Adolesc Med 1995; 149:643-8.

59 Davids JR, Benson L, Mubarak SJ, et al. Ultrasonography and developmental dysplasia of the hip: a cost benefit analysis of three delivery systems. I Pediatr Orthop 1995:15:325-9.

60 Geitung JT, Rosendahl K, Sudmann E. Cost-effectiveness of ultrasonographic screening for congenital hip dysplasia in new-borns. Skeletal Radiol 1996;25:251-4.

61 Clegg J, Bache CE, Raut VV. Financial justification for routine ultrasound screening of the neonatal hip. J Bone Joint Surg Br 1999;81:852-7. 